\title{
Life Water Demand Prediction and Water Security for West Liaohe River
}

Danjun Li, Xingpeng Liu, Jiquan Zhang* , Feng Zhang

School of Environment, Northeast Normal University, Institute of Natural Disaster Research, Northeast Normal University, Changchun 130024, China

\section{西辽河流域生活需水量预测及用水安全分析 \\ 李丹君, 刘兴朋, 张继权", 张峰 \\ 东北师范大学环境学院, 东北师范大学自然灾害研究所, 长春 130024 , 中国}

\begin{abstract}
Scientific and reasonable prediction is conducive to the rational allocation of water resources, using 2008-2013 statistical yearbook data to calculate life water consumption, with the help of gray prediction GM $(1,1)$ model the water demand is simulated, the error between actual water consumption and prediction is small, The model is suitable for the west liaohe river basin. Further life water demand for the time series was analyzed, the oscillation characteristics are obtained,which shows the time trend of life water demand clearly.based on this, we could regulation of water resources allocation reasonable.
\end{abstract}

Keywords: Life water demand,Grey prediction GM $(1,1)$,Water safety analysis

\begin{abstract}
摘要
科学合理进行水资源的预测有利于其合理 分配, 利用 2008 年-2013 年统计年鉴数据 计算各区生活用水量, 借助灰色预测 $\mathrm{GM}(1$, 1)模型对需水量进行了模拟, 结果同实际用 水量误差较小, 该模型适用于西辽河流域。 进一步对生活需水量进行了时间序列的分 析, 得出其震荡特征使得生活需水量的时间 趋势明确展现, 可以依据趋势变化合理调控 水资源分配情况, 进一步的对水资源用量安
\end{abstract}

*通讯作者: Zhangjq022@nenu.edu.cn
全做了讨论, 西辽河流域能够保证该区域居 民生活用水量, 但是需要在未来进行合理的 水资源配置以便适应区域发展需求。

关键词: 生活需水量; 灰色预测 $\operatorname{GM}(1,1)$; 水安全分析

\section{1. 引言}

水资源是人类生存和生活的必需品, 是影响 国家经济发展和国民生活质量的一个重要 因素。我国的水资源具有着时空分布不均的 特点, 在地理位置上呈现出 “东南多, 西北 少”, 而在同一地区, 不同的时间分布差异 较大。这种背景下, 合理地对水资源进行开 发和利用才能有效的缓解我国用水压力。合 理配置水资源就需要对该地区的不同种类 的用水量有定量的了解, 才能够依据已知的 用水量对未来需水量进行预测, 以达到合理 规划和管理水资源的目的。需水量指的是满 足一个地区工业、农业、生活、生态发展等 所需要的水资源量。我国的人口数量具有连 年上升的趋势, 随着人口的不断增加, 生活 需水量也会日益增长, 因此对生活需水量进 行预测显得尤为必要。

目前, 生活需水量的预测分为了定性预 测和定量预测两种; 定性预测是指利用社会 调查的方式, 进行部分预测整体的估算, 这 种方法较为简单, 但是相应的影响因素过 多, 可能导致估算结果与实际偏差较大。定 量预测指的是结合数理统计方法建立符合 实际情况的数学模型进行预测, 较为真实客 
Risk Analysis and Crisis Response in Big Data Era (RAC-16)

观, 在数值表达方面也更为准确 ${ }^{[11}$ 。因此, 本文结合了西辽河流域相关统计年鉴数据, 用 GM $(1,1)$ 灰色预测模型对其流域内生活 需水量进行预测, 进而对其发展趋势做出相 应分析，以便对该流域内水资源科学分配及 政策的拟定提供一定的依据。

\section{2. 研究区概况}

辽河是中国七大河流之一, 由东、西辽河两 个水系组成, 总长 1430 公里, 流域总面积为 22.9 万平方公里。西辽河流域位于辽河的上 游, 介于 $116^{\circ} 20^{\prime} \sim 121^{\circ}$ E、 $41^{\circ} 20^{\prime} \sim 45^{\circ}$ $20^{\prime} \mathrm{N}$ 之间 ${ }^{\mathbf{2 1}}$, 流域面积约占 $64.3 \%$, 流域 涉及的行政区划有内蒙古宁城县、喀喇沈 旗、元宝山区、敖汉旗、翁牛特旗, 内蒙古 克什克腾旗、林西县、巴林右旗、阿鲁科尔 沁旗、翁牛特旗等共 10 个盟市, 27 个旗县 区。

西辽河平均水资源总量为 70.16 亿 $\mathrm{m}^{3}$, 其中地表水资源量为 29.59 亿立方米, 地下 水资源不重复量为 40.57 亿 $\mathrm{m}^{3}$; 西辽河流域 水资源可利用总量为 35.30 亿 $\mathrm{m}^{3}$, 其中地表 水资源可利用量为 16.01 亿 $\mathrm{m}^{3}$, 平原区浅层 地下水可开采量为 31.12 亿 $\mathrm{m}^{3}$ 。近年来, 西 辽河面临着严重的水质污染和水土流失、土 壤肥力逐年减退以及旱灾面积逐年扩大等 问题 ${ }^{21}$, 因此, 我们需要科学合理地对西辽 河水资源进行利用，才能更好的适应该流域 的生态系统退化的现状。

\section{3. 研究方法}

\section{1 生活需水量数学模型}

由于生活环境不同导致生活用水量存在很 大的差异，生活用水包括城镇生活用水和农 村生活用水, 其中, 城镇生活用水由居民用 水和包含餐饮业、服务业、货运邮电业及建 筑业等用水在内的公共用水组成, 农村生活 用水除居民生活用水外还包括牲畜用水在 内 $^{\mathbf{2} 31}$ 。

其中, 居民生活需水量计算公式如下:

$W_{L}=\frac{\sum_{i=1}^{N}\left(W_{c i}+W_{R i}\right) \times 365}{1000}=\frac{\sum_{i=1}^{N}\left(P_{c i} k_{c i}^{S}+P_{c i} k_{c i}^{P}+P_{R i} k_{R i}^{S}+P_{R i} k_{R i}^{P}\right) \times 365}{1000}$

(1)
式（9）中, WL 为居民生活需水量, $\mathrm{m} 3$; N 为将研究区域划分的单元个数; Wci、WRi 分 别为单个单元的城镇、农村居民生活需水 量, $\mathrm{m}^{3} ; P_{c i} 、 P_{R i}$ 分别为单个单元的城镇、 农村人口数; $k_{c i}^{S} 、 k_{c i}^{P}$ 分别为单个单元山区、 平原中的农村人均生活综合需水定额, L/ $($ 人 $\cdot d)$ 。这里, 我们获取的统计年鉴的 数据并未划分平原和山区, 所以我们可以简 化该公式为:

$$
W_{L}=\frac{\left(\mathrm{W}_{C}+\mathrm{W}_{R}\right) \times 365}{1000}
$$

\section{2 灰色预测 GM $(1,1)$ 模型}

灰色预测主要是依据现有的数据, 归纳出数 据序列的变化规律, 进而生成表达变化规律 的微分方程, 以达到预测发展趋势的目的。 由于对居民生活需水量的影响因素较多, 经 济、社会、人口等各个方面均有涉及, 我们 从统计年鉴入手, 获取到的生活用水量和人 口数量远远不够去进行精确预估。灰色预测 模型则可以对统计数据较少的短期时间序 列内有较高精度的预测 ${ }^{21}$ 。因此在本文中, 我们运用灰色预测 GM $(1,1)$ 模型对生活需 水量进行预测估算。

灰色 GM $(1,1)$ 模型目的是将规律不明 显的序列转换成为具有较明显的时间规律 的序列, 进而依据已有数据对未知数据进行 预测。因此需要我们建立好已有的生活用水 量和时间的函数关系。将已获取的生活用水 量数据表示成原始序列为:

$$
X^{(0)}=\left\{\mathrm{x}^{(0)}(1), \mathrm{x}^{(0)}(2), \cdots \mathrm{x}^{(0)}(\mathrm{n})\right\},
$$

对原始序列做累加处理获得累加序列 $X^{(1)}$ :

$$
X^{(1)}(\mathrm{k})=\sum_{i=1}^{k} x^{(0)}(\mathrm{i}), \mathrm{k}=1,2, \cdots, \mathrm{n}
$$

则累加数列估计值的一阶线性微分方程即 $\mathrm{GM}(1,1)$ 基本模型为:

$$
x^{(0)}(\mathrm{k})+\mathrm{az} \mathrm{z}^{(1)}(\mathrm{k})=\mathrm{b}
$$

公式中, $a 、 b$ 分别为系统发展灰数、系统能 
Risk Analysis and Crisis Response in Big Data Era (RAC-16)

生控制灰数, 两者均为待定参数。

式 (1) 所对应的微分方程为:

$$
\frac{d x^{(1)}}{d t}+a x^{(1)}=b
$$

按微分方程的求解方法可得:

$$
x^{(1)}(\mathrm{t})=\left(\mathrm{x}^{(1)}(1)-\frac{b}{a}\right) e^{-a t}+\frac{b}{a}
$$

为求得待定参数 $\mathrm{a} 、 \mathrm{~b}$, 设 $\hat{a}=\left(\begin{array}{l}a \\ b\end{array}\right)$ 为待估参数 向量, 利用最小二乘法求解得:

$$
\hat{a}=\left(\mathrm{B}^{T} \mathrm{~B}\right)^{-1} B^{T} Y
$$

其中,

$$
\begin{gathered}
B=\left(\begin{array}{rr}
-\left[\mathrm{X}^{(1)}(1)+\mathrm{X}^{(1)}(2)\right] / 2 & 1 \\
-\left[\mathrm{X}^{(1)}(2)+\mathrm{X}^{(1)}(3)\right] / 2 & 1 \\
\vdots & \vdots \\
-\left[\mathrm{X}^{(1)}(\mathrm{n}-1)+\mathrm{X}^{(1)}(2)\right] / 2 & 1
\end{array}\right) \\
Y=\left[\begin{array}{c}
X^{(0)}(2) \\
X^{(0)}(3) \\
\vdots \\
X^{(0)}(\mathrm{n})
\end{array}\right]
\end{gathered}
$$

式中, $B$ 为数据矩阵, $Y$ 为数据向量。 则微分方程的解为:
$X^{(1)}(\mathrm{k})=\left[X^{(0)}(1)-\frac{b}{a}\right] e^{-a(\mathrm{k}-1)}+\frac{b}{a}, k=2,3, \cdots \quad(8)$ 即为需水量预测 GM $(1,1)$ 模型的时间响应 函数。将式（6）应用于需水量预测时可表 示为:

$$
x^{(1)}(\mathrm{k}+1)=\left(x^{(0)}(1)-\frac{\mathrm{b}}{a}\right) e^{-a k}+\frac{b}{a}, k=1,2, \cdots, n
$$

式 (7) 即为需水量预测模型 ${ }^{[11}$ 。

\section{4. 西辽河流域生活需水量预测}

本文主要将流域划分为通辽和赤峰两个区 域, 由 2008 年到 2013 年的内蒙古统计年鉴 获取到了不同地市（旗）的农业人口数和非 农业人口数、农村城镇居民需水定额, 利用 公式 (1) 进行计算。利用 2008 年到 2013 年西辽河流域不同县市的居民生活用水量 计算得出 2008 年到 2013 年西辽河流域通辽 市和赤峰市总的居民生活用水量。

\section{1 灰色预测 GM $(1,1)$ 模型}

通过对 2008 到 2013 年的西辽河流域总居民 生活用水量统计数据（表 1) 进行处理可以 得到通辽和赤峰的 GM $(1,1)$ 模型预测结果列 入表 2 。

表 1. 灰色 GM $(1,1)$ 模型预测和实际值对比结果 (单位: $\mathrm{m}^{3}$ )

\begin{tabular}{|c|c|c|c|c|c|c|}
\hline & 2008 & 2009 & 2010 & 2011 & 2012 & 2013 \\
\hline $\begin{array}{c}\text { 通 } \\
\text { 辽 }\end{array}$ & 75847849.72 & 79003150.99 & 81425160.68 & 83130456.01 & 86386604.22 & 91323874.28 \\
\hline $\begin{array}{c}\text { 模 } \\
\text { 拟 }\end{array}$ & 75847849.72 & 78930659.69 & 81251122.93 & 83639804.90 & 86098711.15 & 88629906.19 \\
\hline $\begin{array}{c}\text { 赤 } \\
\text { 峰 }\end{array}$ & 100735379.1 & 105244874 & 109289862.9 & 111980905 & 120061813 & 126666352 \\
\hline $\begin{array}{l}\text { 模 } \\
\text { 拟 }\end{array}$ & 100735379.1 & 104609137.14 & 109152890.86 & 113894004.95 & 118841051.87 & 124002976.40 \\
\hline
\end{tabular}

表 2. 灰色 $\mathrm{GM}(1,1)$ 模型预测值（单位: $\mathrm{m}^{3}$ )

\begin{tabular}{|c|c|c|c|c|c|c|c|}
\hline & 2014 & 2015 & 2016 & 2017 & 2018 & 2019 & 2020 \\
\hline $\begin{array}{l}\text { 通 } \\
\text { 辽 }\end{array}$ & 91235515.21 & 93917725.90 & 96678790.25 & 99521026.46 & 102446820.87 & 105458630.01 & 108558982.59 \\
\hline $\begin{array}{l}\text { 赤 } \\
\text { 峰 }\end{array}$ & 129389111.90 & 135009197.05 & 140873393.61 & 146992304.67 & 153376993.91 & 160039005.53 & 166990385.18 \\
\hline
\end{tabular}


Risk Analysis and Crisis Response in Big Data Era (RAC-16)

灰色 GM $(1,1)$ 模型对通辽和赤峰在置信 水平为 $90 \%$ 的条件下进行拟合和预测的百分 平均相对误差分别为： $0.31287 \%$ 和 0. $86364 \%$; 利用已有的 2013 年的数据进行 判别 (即利用预测同实际的差值的绝对值比 上实际值），分析发现通辽和赤峰的误差分 别为: 0.0295 和 0.0210 , 可见利用灰色 GM (1, 1) 模型预测的结果是较为符合真实情况的。

\section{2 需水量时间序列分析}

通过观察图 1 中所示的 2008 到 2013 年通辽 和赤峰的生活用水量的条形图我们可以看 出总体来看生活用水量呈现出逐年上升的 趋势。我们利用小波函数来进行生活需水量
的时间序列的趋势预测分析。由于本文研究 的是生活需水量的年际变化, 并且属于小样 本数据, 因此我们借助 mat $1 \mathrm{ab}$ 中小波分析 对数据样本进行处理。随着小波层数的分 解, 可以获得序列的低频信息, 有助于获得 其趋势特性。

从 2008 年到 2013 年加之利用灰色 GM $(1,1)$ 模型预测的 2013 到 2020 年的生活 需水量数据可以得出西辽河流域整体的生 活用水趋势是不断上升的。

进一步的对已有的数据进行复 Morlet 小波函数处理得到其小波变换等值线图 (图 2), 可以看出: 图的中上部分线较细密, 下 部分较为稀疏, 分别对应了较短时间尺度和

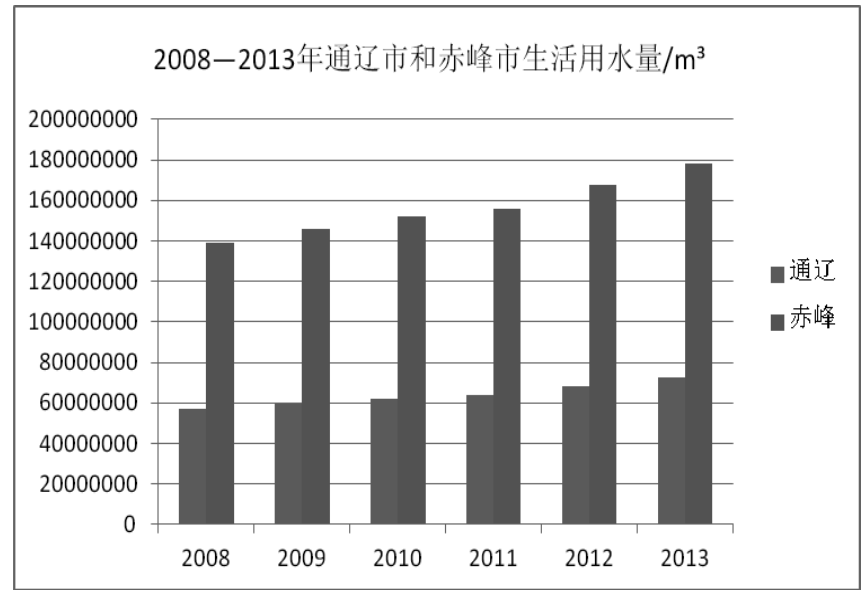

图 1. 2008-2013 年通辽市和赤峰市生活用水量条形示意图

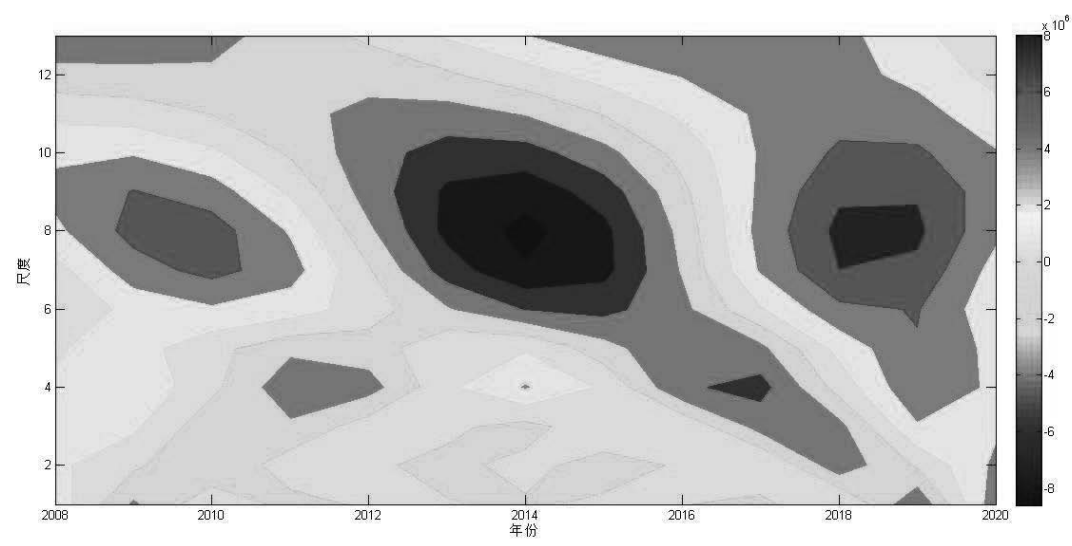

图 2 2008一-2020 年通辽市和赤峰市平均生活用水量小波分析图 


\section{Risk Analysis and Crisis Response in Big Data Era (RAC-16)}

较长时间尺度的周期震荡, 表现出了较为明 显的 8 年左右的周期震荡。从 10 年尺度看, 有 3 个较强的震动中心, 分别位于 2010 年 附近，2014 年附近和 2018 年附近，从 5 年 尺度看, 有 3 个较弱的震动中心分别位于 2011 年附近, 2014 年附近和 2017 年附近。 两个突变点分别位于 2012 年和 2016 年。用 水量多的时期是 2008-2012 年和 20172020 年, 用水量较少的时期为 2012 年到 2016 年。因此， 2017 年到 2020 年作为用水 量较多的年份, 我们可以依据已有的预测数 据, 来合理调配水资源以达到科学用水的目 的。

\section{3 水安全分析}

水安全主要包含了两方面的意义: 一方面是 水量的, 既能满足生产生活的使用, 又达不
到洪涝灾害的临界值; 另一方面是水质的安 全, 保障水体不受到污染, 适合人类使用需 求 ${ }^{\mathbf{8 1}}$ 。其中, 水资源量的保障是地区用水的 基本要求。绝对的用水安全是过于理想化 的, 我们只能通过提早的预测和预防来使得 地区用水尽量有安全保证 ${ }^{\mathbf{9} 1}$ 。而西辽河流域 是我国干旱较为严重的地区之一。该地年均 降雨量少, 蒸发量大, 随着人口不断增加, 灌溉用水量增大, 经济发展用水需求增大, 导致了西辽河经常性断流。据资料, 辽河的 水资源开发率已经达到了地表水 $50 \%$, 地下 水 $86 \%$ 的程度, 早已超过了国际公认临界值 - - $40 \%{ }^{\mathrm{I}}{ }^{\mathrm{I}}$ 。翁牛特旗一库伦旗一带是西辽 河的严重缺水区域 ${ }^{51}$, 虽然内蒙古的人均水 资源量为 $2200 \mathrm{~m}^{3}$, 依据表 3 , 属于轻度缺水 地区, 但是西辽河流域本身的干旱情况, 需 要重新估计该地的缺水情况。

表 3 国际通用水资源紧缺指标

\begin{tabular}{ccc}
\hline 紧缺性 & 人均水资源量 $\left(\mathrm{m}^{3}\right)$ & 主要问题 \\
\hline 轻度缺水 & $1700-3000$ & 局部地区、个别时段出现水问题 \\
\hline 中度缺水 & $1000-1700$ & 将出现周期性和规律性用水紧张 \\
\hline 重度缺水 & $500-1000$ & 将持续性缺水, 经济发展受到损失, 人体健康受 \\
& & 影响 \\
\hline 极度缺水 & $<500$ & 将经受极其严重的缺水, 需要调水 \\
\hline
\end{tabular}

\section{5. 总结与讨论}

本文基于已有的 2008-2013 年的统计数据, 采用数学模型计算得出了西辽河流域的生 活用水量, 进一步依据 GM $(1,1)$ 模型对生 活需水量进行了预测, 获得的模拟数据与真 实的用水量平均误差为 $2.5 \%$, 因此对该流域 的生活需水量预测可以利用灰色预测进行。 依据模型预测的 2014-2020 年的需水量数 据进行 2008-2020 年的生活需水量的小波 分析, 可以看出生活需水量的振荡周期约在 8 年左右, 依据需水量的变化进一步可以进 行水资源安全评价, 以应对需求越来越大的 生活用水情况，提高水资源利用率，科学规 划水资源分配比，使得西辽河流域用水量有 所保障, 为该地区水安全工作提供一定帮 助。

\section{Acknowledgements}

The study is financially supported by the Nat ional Non-Profit Research Program of China (No.201401015).

\section{致谢}

本研究得到了基金项目：水利部公益性行业 科研专项经费项目（201401015）的资助。

\section{参考文献:}

[1] 甘月云, 陈星, 付军, 等. 基于灰色预测 $\operatorname{GM}(1,1)$ 模型的城镇生活需水量预测. 水电能源科学, 2012(9):40-42.

[2] 胡金明, 崔海亭, 李宜垠. 西辽河流域全 新世以来人地系统演变历史的重建. 地 理科学, 2002, 22(5):535-542.

[3] 李大鸣, 赵明雨, 徐好梅, 等. 子牙河流 域社会经济需水量数学模型. 天津大学 
Risk Analysis and Crisis Response in Big Data Era (RAC-16)

学报:自然科学与工程技术版, 2014, 47(4):355-363.

[4] 王丽娟. "引绰济辽"工程是解决西辽河 流域资源性缺水的重要途径. 内蒙古科 技与经济, 2005(22):9-9.

[5] 高秀花, 何江涛, 段青梅,等. 西辽河(内 蒙古)严重缺水区地下水资源及开发利 用对策. 西北地质, 2005, 38(1):83-88.

[6] 叶文宇, 白丹, 高彬. 西安城市生活需水 量预测. 水资源与水工程学报, 2005, 26(3):62-64.

[7] 张雅君, 刘全胜, 冯萃敏. 多元线性回归
分析在北京城市生活需水量预测中的应 用. 给水排水, 2003, 29(4):26-29.

[8] 张翔, 夏军, 贾绍风. 水安全定义及其评 价指数的应用. 资源科学, 2005, 27(3):145-149.

[9] C. Song, Z. Ren, A. Zhou, et al. Water security risk assessment of the yellow river basin based on constrained-random weight and cloud model. Journal of Risk Analysis and Crisis Response, 2013, 3(4):201-209. 